\title{
Predicting Business Distress Using Neural Network in SME-Arab Region
}

\author{
Al Khatib Malek ${ }^{a}$, Genanew B.Worku ${ }^{b}$, Ananth Rao ${ }^{c, *}$ \\ ${ }^{a}$ Risk Department, Euler Hermes, Dubai, United Arab Emirates, alkhateeb.mlk@gmail.com \\ ${ }^{b}$ Dubai Business School, University of Dubai, Dubai, United Arab Emirates, gbekele@ud.ac.ae \\ ${ }^{c}$ Dubai Business School, University of Dubai, Dubai, United Arab Emirates, arao@ud.ac.ae \\ ${ }^{*}$ Corresponding author.
}

Received: 16 June 2017, revised: 4 September 2017, accepted: 7 September 2017, published: 15 April 2018

\begin{abstract}
The paper analyzes the financial and operational measures for Small and medium-sized enterprises (SME) business distress for predicting credit worthiness by using panel data of 110 observations from 22 SME companies for a period of 5 years (2009 - 2013). Panel logistic and Neural Network (NN) models are developed as alternative techniques for predicting the business distress. The result suggests that cash cycle, net fixed assets, and leverage ratio are key factors in making credit decisions by lenders. The logistic model overall correctly classified 70 percent while NN framework outperformed the logistic model with 93 percent overall correct classification in training phase, and 83 percent in testing phase. The study opens up potential opportunities for the lending firms to adopt advanced analytical frameworks for predicting distress behavior of business firms.
\end{abstract}

Keywords: SME, Business distress, Arab region, Petrochemical sub-sectors, Logit Model, Neural Network.

JEL codes: G29, G32

\section{INTRODUCTION}

Small and medium-size enterprises (SME) are growing fast in developing and emerging markets. In Egypt, SME constitute more than 95 percent of all non-agricultural private enterprises and account for nearly 75 percent of new employment generationi. In Kuwait, SME constitute approximately 90 percent of the private workforce. In Lebanon, more than 95 percent of total enterprises are SME and contribute about 90 percent of the jobs. In the UAE, SME account for 94.3 percent of economic projects. Currently, the total exposure of banks to SME in the UAE accounts for about 5 percent of total lending while their contribution to total bank deposits is about 6 percent (Cedar Consulting - Gulf news, 17th November 2015). In Yemen, SME account for 96 percent of the GDP in 2005. In Algeria, Palestine and Saudi Arabia; SME accounted for 77, 59, and 25 percent of the respective country's GDP in 2009 (Emine, 2012).

Easy access to finance for SME helps to direct development efforts at the upstream end of value chains. This is one of the elements needed to build domestic productive capacityii. SME and especially start-up businesses face many challenges in accessing finance compared to corporate institutions. In the Arab region, SME's access to credit facilities is still not impressive. For example, SME lending represents only 5.8 percent of total lending portfolio of Abu Dhabi Islamic Bank in 2013iii. In Emirates NBD, SME makes up only 0.27 percent of the total group's lending portfolioiv. In Arab Bank plc, SME represented only 3.4 percent of the lending portfoliov. As UAE is concerned with asset quality, the SME experience a difficult business environment resulting in delays and/or defaults in loan repayments (Gulf news, 17th November 2015). 
Furthermore, Basel II requirement of capital adequacy ratio of greater than 8 percent imposed further restrictions on banks' lending to SME. In 2012, the Basel capital requirement was further revised, and banks were given the option to use a more risk-sensitive approach for calculating the regulatory capital charge for credit risk - based on their own rating procedures in which the credit risk weights are determined using borrower-based risk parameters (also referred to as Internal Ratings Based (IRB) approach). Banks in the Arab region often do not have credit scoring model that can help them to ease the Basel II requirements, especially for SME. Thus the problem of modeling credit risk specifically for SME has either not been addressed or has only been scantily considered, compared to corporate debtors. Governments and SME associations have also complained that banks impose high interest rates when lending to SME in addition to credit rationing. Given the importance of SME in the economy, such restrictions on SME certainly retard economic growth. The Central Bank of the UAE requires that, banks must use at least 3 years of retail client data (to start with) to estimate loss characteristics and gradually increase to 5 years of data at the time of full implementation of the Basel framework in $2016^{\mathrm{vi}}$.

In the Arab region, unlike corporate and listed companies, financial data of SME is not always available, or partially disclosed for taxation purposes. Banks are realizing that SME are a distinct kind of clients with specific needs that require risk management tools and methodologies specifically developed and adapted for them to improve banks' financing decisions. On the other hand, there is no single definition of SME among banks in the Arab region, UAE Central Bank defines SME where annual sales should be between AED 7.5 million (USD 2.04 Million) and AED 75 million (USD 20.4 Million). The Central Bank of Jordan has a similar approach but with lower values. Other criteria such as asset size, number of employees, and the geographical area of the activity are used by the Euro commission and USA banks to define SME in order to distinguish them from corporate debtors.

This paper addresses the problem of business distress of SME operating in the Arab region. The specific measurable objectives of the study are:

1. Develop a Logistic and Neural Network (NN) framework to predict distress behavior of entities in the Arab region.

2. Evaluate the early signs of business distress related to SME engaged in manufacturing subpetrochemical products which includes producing plastic items, food packaging and containers, fertilizers, shopping bags, carpets, hygiene products and non-woven, plastic pipes and other essential and often disposable applications that are used regularly in daily life.

We focus on the manufacturing sub-petrochemical sector particularly because, such entities are increasing in number in the Arab region, and are actively supported by the government to enhance domestic production activities, and the raw materials are in abundance domestically. For instance, the GCC revenue from the fertilizer production in 2012 was estimated at USD 6.6 Billionvii. It is our belief that, improving SME credit information through developing appropriate credit risk model will help banks to increase credit facilities to SME.

The paper is organized in 5 sections. Section 2 reviews the literature and conducts meta-analysis. Section 3 discusses the methodology and data. While section 4 analyses the results, section 5 concludes the study with recommendation for further research.

\section{LITERATURE REVIEW}

Meta-analysis of the literature showed inconsistency of the variables used in analyzing distress of SME (Table 1). Two studies used sales volume for defining mid-size firms, and 2 studies used number of employees for defining SME. Only 3 studies used leverage, one study used profit margin, and one study used cash cycle as independent variable for analyzing business distress of the firms. Most of the studies used logistic regression as a tool by employing a wider set of discriminatory variables which are adopted in our study. 
Table 1: Summary of Meta-Analysis of related studies

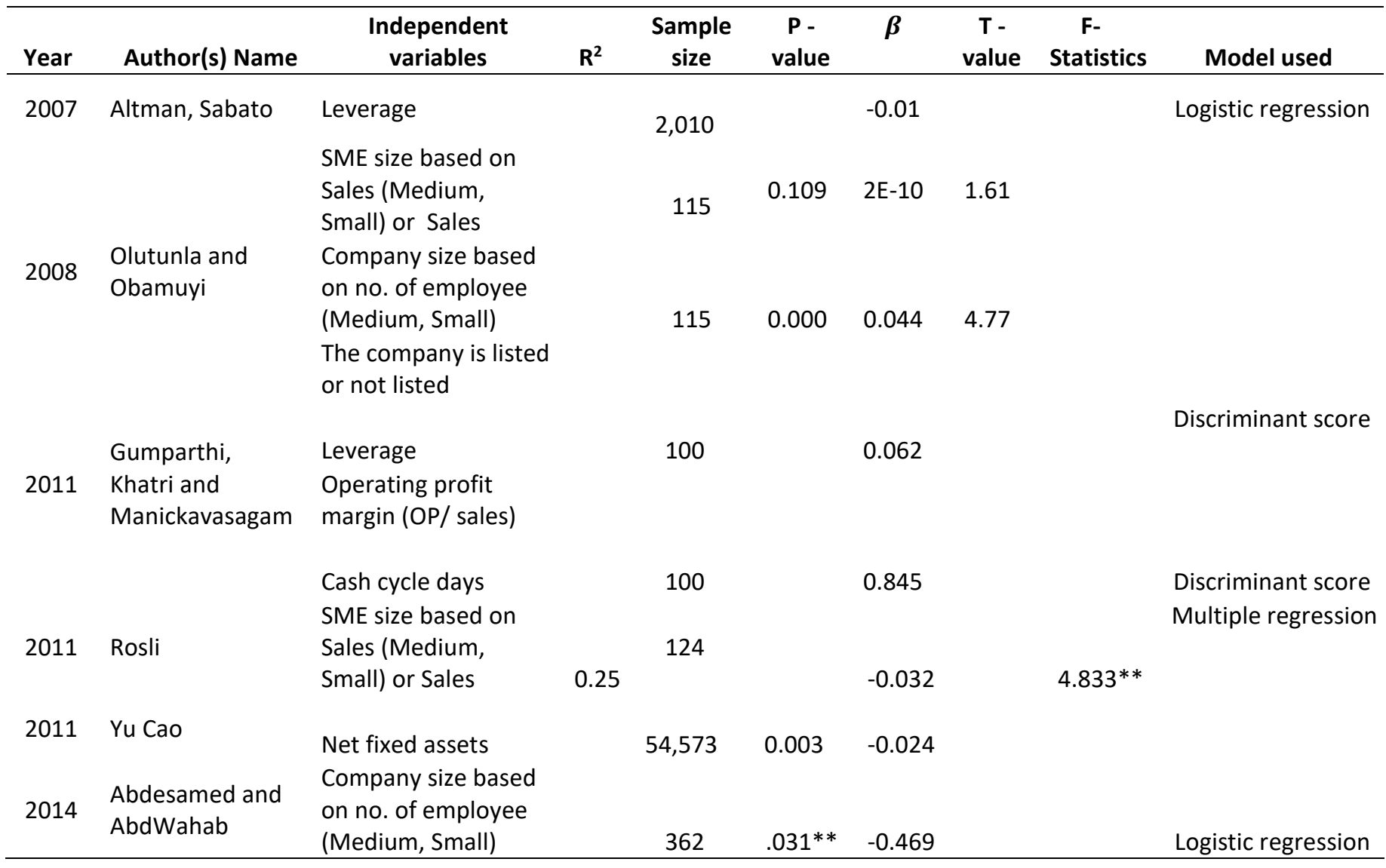

Besides those contained in Table-1, Hashim and Abdullah (2002) surveyed criteria for categorizing the entities as SME. They defined SME in terms of number of employees which in USA ranged between 250 to 1500 persons, and less than 200 employees in UK. They stated that measures such as paid up capital and annual turnover are prone to inflationary effect to define SME. They advocated qualitative measures such as: the firms should be actively managed by owners; highly personalized style of owner's management; predominantly local in its area of operations; largely dependent on internal sources of capital to finance its growth; and rarely opting for bank borrowing for defining the SME. The European Commission defines SME as: "The category of micro, small and medium-sized enterprises (SME) which employ fewer than 250 persons and which have an annual turnover not exceeding 50 million euro, and/or an annual balance sheet total not exceeding 43 million euro"viii (Table 2).

Table 2: SME definition threshold by the Europe Commission

\begin{tabular}{lccc}
\hline & Microenterprises & Small enterprises & Medium-sized enterprises \\
\hline Staff & $<10$ & $<50$ & $<250$ \\
Turnover & $\leq € 2$ million & $\leq € 10$ million & $\leq € 50$ million \\
Balance sheet & $\leq € 2$ million & $\leq € 2$ million & $\leq € 43$ million \\
\hline
\end{tabular}

Source: European Commission 2003

Altman and Sabato (2007) used panel data of US firms with annual sales less than $\$ 65$ Million to represent SME. They further classified SME by asset size: Firms with assets less than or equal to $\$ 25$ Million are small firms; firms with assets less than $\$ 25$ Million are medium-size firms. They developed a Logistic distress prediction model specifically for the SME sector to analyze its effectiveness compared to (Z) Score generic corporate model, which can enable a one-year early prediction of default. These researchers used a panel 
data of 2,010 US SME covering all sectors, including 120 defaults from WRDS COMPUSTAT, spanning the time period 1994 to 2002. They validated the model on a hold-out sample of 432 firms. They concluded that the banks enjoyed significant benefits in terms of SME business profitability, which resulted in slightly lower capital requirements (around 0.5 percent) for banks under the Advanced Internal Rating Based (A-IRB) approach of Basle-II. If banks classify their entire SME portfolio as corporate using the A-IRB approach, they would have faced higher capital requirements than under Basel-II. Altman, et al., (2010) define the SME using quantitative measures such as annual turnover, total assets, number of employees, average annual sales receipts and capital employed; as well as qualitative measures such as firm's legal form and industry type. The authors contend that small firms have a lower risk profile compared to larger firms. This fact explains the success of many SME compared to corporate entities in financial crises, and the ability to overcome the domino effect of such crises. The authors also stated that SME often rely heavily on trade finance from suppliers when bank finance is not available to them. The rationale is that; SME may try to boost sales by offering credit to counter competition but without having the financial resources to back this strategy. Moreover, SME extend trade credit to customers as a means of gaining and retaining customers, but the excessive use and extension of trade credit makes the business vulnerable to cash flow difficulties. The authors also suggested that financially distressed SME have higher levels of both trade debts extended to customers and trade credit obtained from suppliers. Trade debtors may also increase because customers may avoid paying suppliers that are showing signs of financial difficulty, or it may be that many SME fail because of late payments by large customers' bargaining power. The authors used working-capital cycle such as total liabilities to quick assets, trade debtors to total assets, and trade creditors to trade debtors as explanatory variables in their study and found positive and significant relation in explaining the failure.

Emine (2012) study supports the fact that the average SME loan portfolio in Arab region is relatively small (less than 8 percent of total loans). Emine developed OLS regression model on a survey data of 300 different sample SMEs in three Arab countries: high income category (Qatar), medium income category (Egypt), and low income category (Mauritania). The paper concluded that; the Arab region has the lowest legal right index among all regions; the credit information index improved in recent years, but the coverage of credit reporting systems is still very limited; the main constraints faced by the SME are the lack of finance, lack of skilled HR, and low technological capabilities; and the scale and scope of lending to SME in GCC (Gulf Cooperation Council) was much lower than in non-GCC Arab countries.

Hudson (1987) argued that SME bankruptcy is mainly influenced by trade creditors since trade credit forms a large proportion of SME liabilities. This study revealed that when small firms experience a decline in performance and financial stress, they extend more credit to customers as accounts receivables and take extended credit from suppliers as account payables. So, the trade creditors' decision to force bankruptcy would depend on its customers' cash position, current indebtedness to the bank, the expected future profits, the liquidation value and interest rates.

To predict business distress in an entity, creditors use their judgmental techniques that are based on history and experience. But this technique is associated with subjectivity, inconsistency and individual preferences motivating decisions (Abdou and Pointon, 2011). Al Khatib and Al Bzour (2011) examined the validity of Altman-Z score model and Kida's model on a sample of 32 listed companies for the period $1990-2006$ to predict the bankruptcy of Jordanian listed companies. Altman-Z model showed 93.8 percent ability to predict financial failure 5 years on the average prior to liquidation, while Kida's model reached only 69 percent of prediction ability.

This study attempts to fill the gap in the business distress prediction literature in that it advances the methodology of predicting business distress technique using logistic and Neural Network (NN) models, none of which have not been developed to their optimum in predicting business distress.

\section{METHODOLOGY}

In this study, we adopt (in addition to logistic model) a new methodology to evaluate the default or distress behavior through neural network framework. In section 3.2, we provide the justification to this new approach and compare the superiority of this framework over the traditional Logit model as NN is devoid of distributional assumptions that are normally seen in econometric techniques. 


\subsection{Logit Model}

Logit is a qualitative choice model. The probability of business distress $(\mathrm{P})$ can be computed as:

$$
\operatorname{Ln}[P \div(1-P)]=\beta_{0}+\beta_{i} \cdot X_{i}+u_{i}
$$

where, $L n$ is the natural logarithm, $X_{i}$ is a vector of independent variables listed in Table 4, $\beta_{i}$ are logistic impact coefficients, and $u_{i}$ are the error terms. The balanced panel data, used in this study, comprised of 28 SME operating in the Arab region for a period of 5 years, 2009 to 2013 (Table 3) in petrochemical subsectors.

Table 3: Number of sampled SME by region

\begin{tabular}{lccccc}
\hline \multicolumn{1}{c}{ Country } & Listed & Not listed & Total & Small* & Medium* \\
\hline Jordan & 9 & 2 & $\mathbf{1 1}$ & 6 & 5 \\
Saudi Arabia & - & 3 & $\mathbf{3}$ & 2 & 1 \\
Kuwait & 1 & - & $\mathbf{1}$ & - & 1 \\
Oman & 2 & - & $\mathbf{2}$ & - & 2 \\
Qatar & - & 4 & $\mathbf{4}$ & 3 & 1 \\
UAE & - & 7 & $\mathbf{7}$ & 2 & 5 \\
Total & 12 & 16 & $\mathbf{2 8}$ & 13 & 15
\end{tabular}

*The companies are classified as "Small" and "Medium" based on number of employees.

Table 4: Definition of Variables

\begin{tabular}{|c|c|c|}
\hline Variable name & & Variable definition \\
\hline Dependent: & & Business Distress (BD) is binary variable where 1 representing SME with \\
\hline Business Distress (BD) & Y & business distress, 0 representing SME with no business distress. \\
\hline \multicolumn{3}{|l|}{ Independent: } \\
\hline Leverage ratio (Leverage) & $\mathrm{X} 1$ & Total liabilities to Owners' Equity ratio \\
\hline Operating profit (OPS) & $\mathrm{X}_{2}$ & Operating profit to sales ratio \\
\hline Cash Cycle & $X_{3}$ & Number of days needed to generate cash from the business. \\
\hline SME based on Sale & $\mathrm{X}_{4}$ & $\begin{array}{l}\text { Non-financial variable. The size of the company based on Sales. This is a } \\
\text { dummy variable of which } 0=\text { small size entity, } 1=\text { medium size entity. }\end{array}$ \\
\hline Log of Net Fixed Assets & $X_{5}$ & Value of fixed assets after depreciation in million US dollars \\
\hline SME based on \# of employees & $X_{6}$ & $\begin{array}{l}\text { Non-financial variable. The size of the company based on number of } \\
\text { employee (binary; } 0=\text { small size entity, } 1=\text { medium size entity). }\end{array}$ \\
\hline Listed SME & $\mathrm{X}_{7}$ & $\begin{array}{l}\text { Non-financial variable; binary variable of which } 1=\text { listed SME's , } 0=\text { not } \\
\text { listed }\end{array}$ \\
\hline Jordan & $\mathrm{X}_{8}$ & Country dummy: 1 if Jordan; 0 otherwise \\
\hline Qatar & $X_{9}$ & Country dummy: 1 if Qatar; 0 otherwise \\
\hline Kuwait & $\mathrm{X}_{10}$ & Country dummy: 1 if Kuwait; 0 otherwise \\
\hline
\end{tabular}

The data for listed companies were obtained from the annual reports published in the stock exchange of the respective countries. The data of unlisted companies were obtained through follow-up visits with the managers and the owners of the companies. The financial data of unlisted companies were audited by independent certified auditors, which minimize the impact of financial window dressing addressed by Ono (2006). Thirty observations (i.e. 6 companies) were kept as hold-out sample for model validation. 
The dependent variable (Business Distress, BD) reflects the operating style of an SME that will impact the trading activity of the business. Referring to the trade credit literature, we postulate that if the SME can obtain easy credit terms from its suppliers and provide shorter credit terms to its customers, then such SME are operating safely with no business distress (i.e. Business Distress, BD, is 0). In such non-distressed SME cash from operating activity will keep flowing uninterruptedly. On the other hand, if the SME faces challenges to obtain easy credit terms from its suppliers and at the same time offers higher credit terms to its customers (in order to assure higher customer retention rate), it will end up blocking the cash flow generated form operating activity. The postulate has economic rational that, the SME struggling for bank financing, often faces difficulties in obtaining the required business credit facilities since already its leverage ratio is high due to accumulated trade payable. In that case, the SME will be operating under distress (i.e. BD is 1). BD is accordingly computed from the cash cycle rate (in days) and the debtor-days ratio.

\subsection{Neural Network Architecture}

Forecasting, classification of risk, and dimensionality reduction or distillation of information from dispersed signals in the market, are three tools for effective portfolio management and broader decision making in volatile economies yielding "noisy" data. How can we efficiently distil information from these market signals for better diversification and effective risk management, or even better stabilization policy? All of these issues may be addressed very effectively with neural network methods.

Most of modern finance and economic theory comes from microeconomic optimization and decision theory under uncertainty. Economics was originally called the "dismal science" in the wake of John Malthus's predictions about the relative rates of growth of population and food supply. But economics can be dismal in another sense. If we assume that our real-world observations come from a linear data generating process, that most shocks are from an underlying normal distribution and represent small deviations around a steady state, then the standard tools of classical regression are perfectly appropriate. However, making use of the linear model with normally generated disturbances may lead to serious misspecification and mispricing of risk if the real world deviates significantly from these assumptions of linearity and normality. Neural network methods, coming from the brain science of cognitive theory and neurophysiology, offer a powerful alternative to linear models for forecasting, classification, and risk assessment in finance and economics. We can learn once more that economics and finance need not remain "dismal sciences" after meeting brain science.

Forecasting simply means understanding which variables lead or help to predict other variables, when many variables interact in volatile economies. This means looking at the past to see what variables are significant leading indicators of the behaviour of other variables. It also means a better understanding of the timing of lead-lag relations among many variables, understanding the statistical significance of these lead-lag relationships, and learning which variables are the more important ones to watch as signals for further developments. Obviously, if we know the true underlying model generating the data we observe in economies, we will know how to obtain the best forecasts, even though we observe the data with measurement error. More likely, however, the true underlying model may be too complex, or we are not sure which model among many competing ones is the true one. So we have to approximate the true underlying model by approximating models. Once we acknowledge model uncertainty, and that our models are approximations, neural network approaches will emerge as a strong competitor to the standard benchmark linear model.

Organizations would like to be able to discriminate good from bad risks by identifying key characteristics of investment candidates. For instance, in a lending environment, a bank would like to identify the likelihood of default on a car loan by readily identifiable characteristics such as salary, years in employment, years in residence, years of education, number of dependents, and existing debt. Similarly, organizations may desire a finer grid for discriminating, from very low, to medium, to very high unacceptable risk, to manage exposure to different types of riskix. Neural nets have proven to be very effective classifiers-better than the state-of-theart methods based on classical statistical methods. All too often we summarize information about large amounts of data with averages, means, medians, or trimmed means, in which a given Forecasting into the future, or out-of-sample predictions, as well as classification and dimensionality reduction models, must go beyond diagnostic examination of past data. We use the coefficients obtained from past data to fit new data and make predictions, classification, and dimensionality reduction decisions for the future. As the saying goes, life must be understood looking backwards, but must be lived looking forward. The past is certainly helpful for predicting the future, but we have to know which approximating models to use, in combination with past data, to predict future events. The medium-term strategy of any enterprise depends on the outlook in the coming quarters for both price and quantity developments in its own industry. The success of any strategy depends on how well the forecasts guiding the decision makers work. 
Diagnostic and forecasting methods feedback in very direct ways to decision-making environments. Knowing what determines the past, as well as what gives good predictions for the future, gives decision makers better information for making optimal decisions over time. In engineering terms, knowing the underlying "laws of motion" of key variables in a dynamic environment leads to the development of optimal feedback rules ${ }^{x}$. Diagnostic examination of past data, forecasting, and control are different activities but are closely related. The policy rule for control, of course, need not be a hard and fast mechanical rule, but simply an operational guide for better decision making. With good diagnostics and forecasting, for example, businesses can better assess the effects of changes in their prices on demand, as well as the likely response of demand to external shocks, and thus how to reset their prices. So it should not be so surprising that good predictive methods are at a premium in research departments for many industries. Until recently, most of the control or decisionmaking analysis has been based on linear dynamic models with normal or log-normal distributions of asset returns. However, finding such a distribution in volatile environments means going beyond simple assumptions of normality or log normality used in conventional models. Of course, when we let go of normality, we must get our hands dirty in numerical approximation, and can no longer plug numbers into quick formulae based on normal distributions. But there are clear returns from this extra effort.

Like the econometric models, a neural network relates a set of input variables $\left\{x_{i}\right\}, i=1,2, \ldots, k$ to a set of one or more output variables, $\left\{y_{j}\right\}, j=1,2, \ldots, k$. The difference between a NN and other approximation methods is that the neural network makes use of one or more hidden layers, in which the input variables are squashed or transformed by a special function, known as a logistic or log sigmoid transformation. While this hidden layer approach may seem esoteric, it represents a very efficient way to model nonlinear statistical processes. In addition to the sequential processing of typical linear systems, in which only observed inputs are used to predict an observed output by weighting the input neurons, the neurons in the hidden layer process the inputs in a parallel fashion to improve the predictions. The connectors between the input variables, often called input neurons, and the neurons in the hidden layer, as well as the connectors between the hidden-layer neurons and the output variable, or output neuron, are called synapses ${ }^{x i}$. This single-layer feedforward or multiperceptron network with one hidden layer is the most basic and commonly used neural network in behavioural economic and financial applications. More generally, the network represents the way the human brain processes input sensory data, received as input neurons, into recognition as an output neuron. As the brain develops, more and more neurons are interconnected by more synapses, and the signals of the different neurons, working in parallel fashion, in more and more hidden layers, are combined by the synapses to

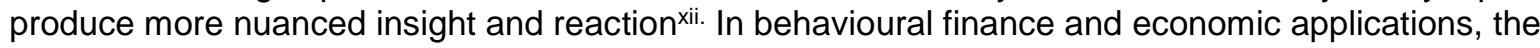
combining of the input variables into various neurons in the hidden layer has another interpretation. Quite often we refer to latent variables, such as expectations, as important driving forces in markets and the economy as a wholexiii. While it is often possible to obtain survey data of expectations at regular frequencies, such survey data come with a time delay. There is also the problem that how respondents reply in surveys may not always reflect their true expectations. The use of the NN to model the process of decision making is based on the principle of functional segregation, which Rustichini et al. (2002) define as "not all functions of the brain are performed by the brain as a whole". A second principle, called the principle of functional integration, states that "different networks of regions (of the brain) are activated for different functions, with overlaps over the regions used in different networks" (Rustichini et al., 2002). Making use of experimental data and brain imaging, they offer evidence that subjects make decisions based on approximations, particularly when subjects act with a short response time. They argue for the existence of a "specialization for processing approximate numerical quantities" (Rustichini et al., 2002).

In a more general econometric framework, NN approximation is a sieve estimator. In the univariate case, with one input $\mathrm{x}$, an approximating function of order $m, \Psi_{m}$, is based on a non-nested sequence of approximating spaces:

$$
\Psi_{m}=\left[\psi_{m}, 0(x), \psi_{m}, 1(x), \ldots, \psi_{m}, m(x)\right]
$$

Each finite expansion $\left\{\psi_{m}, 0(x), \psi_{m}, 1(x), \ldots, \psi_{m}, m(x)\right\}$, can potentially be based on a different set of Jump Connections. One alternative to the pure feedforward network or sieve network is a feedforward network with jump connections, in which the inputs $x$ has direct linear links to output $y$, as well as to the output through the hidden layer of squashed functions, which is analogous to adaptive learning. 


\section{EMPIRICAL MODEL RESULTS \& ANALYSIS}

\subsection{Preliminary Data Statistics}

Table 5 displays summary statistics. As expected skewness of some independent variables are far away from normality and raises the doubt about the validity of using Logistic specification for modeling business distress of SME.

Table 5 Descriptive statistics of independent variables

\begin{tabular}{lccccc}
\hline \multicolumn{1}{c}{ Variables } & & $\mathbf{N}$ & Mean & Std. Dev. & Skewness \\
\hline Leverage & $\mathrm{X}_{1}$ & 140 & 0.486 & 0.502 & 5.821 \\
Operating profit & $\mathrm{X}_{2}$ & 140 & 1.341 & 2.335 & 1.900 \\
Cash Cycle & $\mathrm{X}_{3}$ & 140 & 0.140 & 1.078 & 11.594 \\
SME Size 1 - based on Sales & $\mathrm{X}_{4}$ & 140 & 219.625 & 1444.101 & 2.540 \\
In(Net Fixed Assets) & $\mathrm{X}_{5}$ & 140 & 0.107 & 0.310 & -0.376 \\
SME Size 2 - based on Employees & $\mathrm{X}_{6}$ & 140 & 1.594 & 1.459 & -0.057 \\
Listed SME & $\mathrm{X}_{7}$ & 140 & 0.514 & 0.502 & 0.289 \\
Jordan & $\mathrm{X}_{8}$ & 140 & 0.393 & 0.490 & 0.439 \\
Qatar & $\mathrm{X}_{9}$ & 140 & 0.143 & 0.351 & 2.041 \\
Kuwait & $\mathrm{X}_{10}$ & 140 & 0.036 & 0.186 & 5.004 \\
\hline
\end{tabular}

Regressors set was checked with variance inflation factor (VIF $>10$ ) and results showed no multicollinearity among the repressors. Transition probability of the dependent variable (business distress) was estimated to see how many companies were operating under business distress in the sample. The result is presented in Table 6.

Table 6: Year-to-year transitions probability (\%) in business distress

\begin{tabular}{cccc}
\hline & \multicolumn{3}{c}{ Business distress } \\
\hline Business distress & $\mathbf{0}$ & $\mathbf{1}$ & Total \\
$\mathbf{0}$ & 57.89 & 42.11 & 100 \\
$\mathbf{1}$ & 45.45 & 54.55 & 100 \\
Total & $\mathbf{5 1 . 7 9}$ & $\mathbf{4 8 . 2 1}$ & $\mathbf{1 0 0}$ \\
\hline
\end{tabular}

The result shows that out of 48 percent of the SME experiencing business distress in the current year, 55 percent of them will remain under business distress in the following year. Similarly, out of 52 percent of the SME not showing business distress in the current year, 46 percent are expected to show business distress in the following year.

Table 7 presents the regression results of random effect model (RE), the fixed effect model (FE) and the population-average model (PA)11. The FE model assumes that independent variables do not vary with time, so they are fixed. This assumption may not hold true in our study. For example, if the SME was of small size in 2009, it may not remain small forever in terms of the volume of sales or the number of employees. The RE model takes into consideration the variation of an observation over time. Hence, RE model seems more appealing in the study than the FE model. The Housman test clearly shows that the null hypothesis (that the $\mathrm{RE}$ model is preferable) cannot be rejected; suggesting that $\mathrm{RE}$ provides a better estimate than $\mathrm{FE}$. On the other hand, the likelihood-ratio test of rho $(\rho)$ shows that the null hypothesis (that $\rho=0$ ) cannot be rejected and hence $P A^{\text {xiv }}$ is more appropriate and efficient than RE. 
Table 7: Regression results of RE, FE, and PA.

\begin{tabular}{|c|c|c|c|c|}
\hline \multicolumn{2}{|l|}{ Variables } & \multirow{2}{*}{$\frac{\text { RE Model }}{0.499 * * *}$} & \multirow{2}{*}{$\begin{array}{c}\text { FE Model } \\
0.209\end{array}$} & \multirow{2}{*}{$\begin{array}{l}\text { PA Model } \\
0.520^{* * *}\end{array}$} \\
\hline Leverage & $\mathrm{X} 1$ & & & \\
\hline Operating profit & $\mathrm{X}_{2}$ & -0.044 & 0.019 & -0.043 \\
\hline Cash Cycle & $x_{3}$ & $0.011^{* * *}$ & $0.020 * * *$ & $0.010 * * *$ \\
\hline SME Size 1 (Sale) & $X_{4}$ & -0.519 & (omitted) & -0.233 \\
\hline In(Net Fixed Assets) & $X_{5}$ & -0.321 & 0.445 & $-0.357 * *$ \\
\hline SME Size 2 (Employees) & $X_{6}$ & -0.682 & -15.286 & $-0.621 * * *$ \\
\hline Listed SME & $X_{7}$ & $-2.032^{*}$ & (omitted) & $-1.509 * * *$ \\
\hline Jordan & $X_{8}$ & 1.816 & (omitted) & $1.512^{* *}$ \\
\hline Qatar & $\mathrm{X}_{9}$ & -1.730 & (omitted) & $-1.906 * * *$ \\
\hline Kuwait & $\mathrm{X} 10$ & 1.677 & (omitted) & 1.2673 \\
\hline \multicolumn{2}{|l|}{ Constant } & -0.390 & & -0.289 \\
\hline \multicolumn{2}{|l|}{ Prob > chi2 } & 0.020 & 0.0128 & 0.000 \\
\hline \multicolumn{2}{|l|}{ Log likelihood } & -76.000 & -42.70 & \\
\hline \multicolumn{2}{|l|}{ Wald chi2 } & 24.110 & $14.48^{a}$ & 191.20 \\
\hline \multicolumn{2}{|c|}{$A I C$} & 180.410 & 95.40 & $N / A^{b}$ \\
\hline \multicolumn{2}{|c|}{ Number of observations } & 140 & 125 & 140 \\
\hline \multicolumn{2}{|c|}{ Housman test: Prob > chi2 } & & 0.499 & \\
\hline \multicolumn{2}{|c|}{ RHO $(\rho):$ Prob $>=$ chibar 2} & & 0.498 & \\
\hline
\end{tabular}

Note: *Significant at 10 percent, ${ }^{* *}$ significant at 5 percent, ${ }^{* * *}$ significant at 1 percent. All GCC countries are included, but only those significant are presented. ${ }^{a} L R$ chi2(5); bAIC is not applicable with PA model.

Using PA as a base model, three logistic models were specified as in Table 8. In model (1), we used the number of employees as the definition of the SME, and we transformed the net sales and fixed assets to the logarithmic form. In model (2), we used fixed assets as the definition of the SME and we omitted the fixed assets variable from the model. In model (3), we used the number of sales as the definition of the SME and we omitted the sales variable. The model with the lowest Akaike's information criterion (AIC) is a preferred model. Thus, Model-1 is superior to Model 2 and 3 . The model also showed a 70 percent prediction power. The regression result in model 1 show that a 1 percent increase in the leverage ratio resulted in 45 percent increase in the probability of distress. Likewise, a 1 percent increase in number of days needed to generate cash from the business increased the probability of distress by 39 percent. 
Table 8: Comparison results for the 3 logistic models

\begin{tabular}{|c|c|c|c|c|}
\hline Variables & Model 1 & Model 2 & Model 3 & $\begin{array}{c}\text { Relative } \\
\text { Probability for significant } \\
\text { Model } 1\end{array}$ \\
\hline Leverage $\left(\mathrm{X}_{1}\right)$ & $0.509 * * *$ & $0.585 * * *$ & $0.503 * * *$ & 0.454 \\
\hline Operating profit $\left(\mathrm{X}_{2}\right)$ & -0.026 & -0.054 & -0.052 & 0.385 \\
\hline Cash Cycle $\left(\mathrm{X}_{3}\right)$ & $0.001 * * *$ & $0.009 * * *$ & $0.011 * * *$ & 0.394 \\
\hline SME Size 1 (Sale) $\left(\mathrm{X}_{4}\right)$ & - & - & -0.666 & 0.394 \\
\hline In(Net Fixed Assets) $\left(X_{5}\right)$ & $-0.325^{* *}$ & - & -0.292 & 0.385 \\
\hline SME Size 2 (Employees) ( $\mathrm{X}_{6}$ ) & $-0.687^{*}$ & $-1.010 * *$ & -0.662 & 0.178 \\
\hline Listed SME ( $\left.\mathrm{X}_{7}\right)$ & $-1.836 * * *$ & $-1.591 * *$ & $-2.058 * * *$ & 0.202 \\
\hline Jordan $\left(\mathrm{X}_{8}\right)$ & $1.806 * *$ & $1.740 * *$ & $1.764^{* *}$ & 0.569 \\
\hline Qatar (X9) & $-1.718^{* *}$ & -1.059 & $-1.701^{* *}$ & 0.408 \\
\hline Kuwait $\left(\mathrm{X}_{10}\right)$ & $1.627^{*}$ & 1.301 & 1.587 & 0.337 \\
\hline Constant & -0.4320 & -0.9964 & -0.407 & \\
\hline Prob > chi2 & 0.0001 & 0.0002 & 0.000 & \\
\hline Loglihood & -75.12 & -76.401 & -74.884 & \\
\hline Adjusted $R^{2}$ & 0.225 & 0.212 & 0.230 & \\
\hline$A I C$ & 180.2375 & 180.8017 & 181.77 & \\
\hline Classification & $70 \%$ & $71 \%$ & $69 \%$ & \\
\hline Mean VIF & 2.010 & 1.940 & 2.040 & \\
\hline Number of observations & 140 & 140 & 140 & \\
\hline
\end{tabular}

Note: ${ }^{*}$ significant at 10 percent, ${ }^{* *}$ significant at 5 percent, ${ }^{* * *}$ significant at 1 percent.

The size of fixed assets of SME plays a key role in determining the business distress within the SME. This variable was negatively related to probability of distress and was significant. SME size (based on number of employees) negatively affected the probability of distress. In particular, a 1 percent increase in the SME size-2 decreased the probability of distress by 18 percent. The fact that the SME is listed decreases the probability of distress. The probability of distress among the listed SME was found to be 20 percent less than those that are not listed. While SME located in Jordan and Kuwait have a higher probability of business distress compared to UAE - SME, Qatar-SME have lower probability of distress compared to UAE-SME. The model also correctly classified 74 percent of the distressed firms (specificity) and 66 percent of the non-distressed firms correctly classified (sensitivity). With overall correct classification 70 percent.

\subsection{Model interpretation}

The study found that leverage ratio, cash cycle in days, size of fixed asset, size of SME (based on number of employees), and listing of SME were the key determinants of business distress for SME in Arab region. Country of location of the SME also matters in influencing business distress of SME in the Arab region. A key determinant is the cash cycle in days. The cash cycle reflects the operating style and the ability of the SME to generate cash from its business within the shortest possible time in order to assure adequate cash flow to the business. Given that cash cycle in days (trade debtor days plus inventory turnover in days' minus trade creditor days) if it is longer to generate cash from the business, the higher is the probability of business distress for SME. Therefore, many SME, especially small-size business, plausibly are always looking to obtain longer credit terms from their suppliers to calibrate the cash cycle and make it shorter, by increasing the number of days needed to pay the suppliers.

As the short term borrowing is probably not always affordable, the main liability component in SME is expected to be the trade payables. The study revealed that higher leverage ratio, higher is the probability of business distress for SME. 


\subsection{Neural Network (NN) Analysis}

To overcome the non-normal behavior of data as indicated by the skewness in Table 5, we adopt Neural Network (NN) Analysis for addressing research questions. The appeal of the neural network approach lies in its assumption of bounded rationality: when we forecast in volatile emerging markets, we are approximating the expectations of others. Market participants are thus engaged in a learning process, continually adapting prior subjective beliefs from past mistakes. What makes the neural network approach so appealing in this respect is that it permits threshold responses by economic decision makers to changes in policy or exogenous variables1. In the neural network model, one is not making any specific hypothesis about the values of the coefficients to be estimated in the model, nor, for that matter, any hypothesis about the functional form relating the observed repressor " $x$ " to an observed output " $y$ ". Most of the time, we cannot even interpret the meaning of the coefficients estimated in the neural network, at least in the same way we can interpret estimated coefficients in ordinary econometric models, with a well-defined functional form. In that sense, the neural network differs from the usual econometrics, where considerable effort is made to obtain accurate and consistent, if not unbiased, estimates of particular parameters or coefficients. Similarly, when nonlinear models are used, too often economists make use of numerical algorithms based on assumptions of continuous or "smooth" data. All too often, these methods break down, or one must make use of repeated estimation, to make sure that the estimates do not represent one of several possible sets of local optimum positions. Various sectors of emerging markets, in particular, with a great deal of innovation and change, represent a fertile ground for the use of neural network for two reasons, which are interrelated. One is that the data are often very noisy, due either to the thinness of the markets or to the speed with which news becomes dispersed, so that there are obvious asymmetries and nonlinearities that cannot be assumed away. Second, in many instances, the players in these markets are themselves in a process of learning, by trial and error, about policy news or about legal and other changes taking place in the organization of their markets. The parameter estimates of a neural network, by which market participants forecast and make decisions, are themselves the outcome of a learning and search process.

The total samples used are 110 (net of 30 data which were excluded with missing information on some variables) with 10 inputs and two output that represents whether the SME is in business distress or not, and it is divided into two kinds of samples for the purpose of experimentations as in Table 9:

Table 9. NN Processing Summary

\begin{tabular}{llcc}
\hline & & $\mathrm{N}$ & Percent \\
\hline \multirow{2}{*}{ Sample } & Training & 75 & $68.2 \%$ \\
& Testing & 35 & $31.8 \%$ \\
Valid & 110 & $100.0 \%$ \\
Excluded (missing variables & 30 & \\
Total & 140 & \\
\hline
\end{tabular}

As presented in table 9, 75 data samples have been assigned for the training phase, and the network is adjusted according to its error. On the other hand, 35 data samples have been assigned for the validation phase. These were used to measure network generalization, and to halt training when generalization stabilizes at a certain range. The training is done using backpropagation neural networks with 4 hidden neurons using Softmax Cross Entropy (CE) results. Lower values of error results are better. Zero means no error.

The procedure for using NN includes selecting data, create and train a network, and evaluate its performance using cross-entropy matrices. A one-layer feed-forward network, with hyperbolic-tangent hidden layer and softmax output neurons can classify distress data vectors arbitrarily well, given enough neurons in its hidden layer. In our experiments, the number of hidden layer that gave best performance is 4 neurons (Figure 4.1 and Table 10). 
Table 10. Network Information

\begin{tabular}{|c|c|c|}
\hline Input Layer & $\begin{array}{l}\text { Number of Units }{ }^{\mathrm{a}} \\
\text { Rescaling Method for Covariates }\end{array}$ & $\begin{array}{c}10 \\
\text { Standardized }\end{array}$ \\
\hline \multirow[t]{3}{*}{ Hidden Layer(s) } & Number of Hidden Layers & 1 \\
\hline & Number of Units in Hidden Layer $1^{\mathrm{a}}$ & 3 \\
\hline & Activation Function & Hyperbolic Tangent \\
\hline \multirow[t]{4}{*}{ Output Layer } & Dependent Variables & $\mathrm{Y}$ \\
\hline & Number of Units & 2 \\
\hline & Activation Function & Softmax \\
\hline & Error Function & Cross-entropy \\
\hline \multicolumn{3}{|c|}{ Excluding the bias unit } \\
\hline \multirow[t]{4}{*}{ Training } & Cross Entropy Error & 14.793 \\
\hline & Percent Incorrect Predictions & $6.7 \%$ \\
\hline & Stopping Rule Used & 1 consecutive step(s) with no decrease in errora \\
\hline & Training Time & 0:00:00.03 \\
\hline \multirow[t]{2}{*}{ Testing } & Cross Entropy Error & 16.649 \\
\hline & Percent Incorrect Predictions & $17.1 \%$ \\
\hline
\end{tabular}

Table 11 displays the model error classification. In training phase, the average percent correct prediction of business distress was 88.1 percent and that of non-distress was 100 percent, with overall correct prediction of 93.3 percent compared to 70 percent overall correct classification in Logistic model discussed in previous section.

Similarly, in testing phase, the average percent correct prediction of business distress was 77.8 percent and that of non-distress was 88.2 percent, with overall correct prediction of 82.9 percent.

Table 11. Classification

\begin{tabular}{lcccc}
\hline & & \multicolumn{3}{c}{ Predicted } \\
\cline { 3 - 5 } Sample & Observed & 0 & 1 & Percent Correct \\
Training & 0 & 33 & 0 & $100.0 \%$ \\
& 1 & 5 & 37 & $88.1 \%$ \\
\multirow{3}{*}{ Testing } & Overall Percent & $50.7 \%$ & $49.3 \%$ & $93.3 \%$ \\
& 0 & 15 & 2 & $88.2 \%$ \\
& 1 & 4 & 14 & $77.8 \%$ \\
& Overall Percent & $54.3 \%$ & $45.7 \%$ & $82.9 \%$ \\
\hline
\end{tabular}

Table 12 and the accompanying figure (Figure 4.2) shows the importance of factors in NN model in the order of decreasing importance for explaining the distress behavior of firms in the Arab region. Some of these variables were insignificant in the Logistics model.

Thus variables such as cash cycle, operating profit, net fixed assets, and the leverage were of importance to the degree of $100 \%, 57.9 \%, 44 \%$ and $40 \%$ respectively in explaining the business distress in the Arab region. 
Figure 4.1 Feed Forward Neural Network with 10 inputs, 4 hidden neurons, and two output

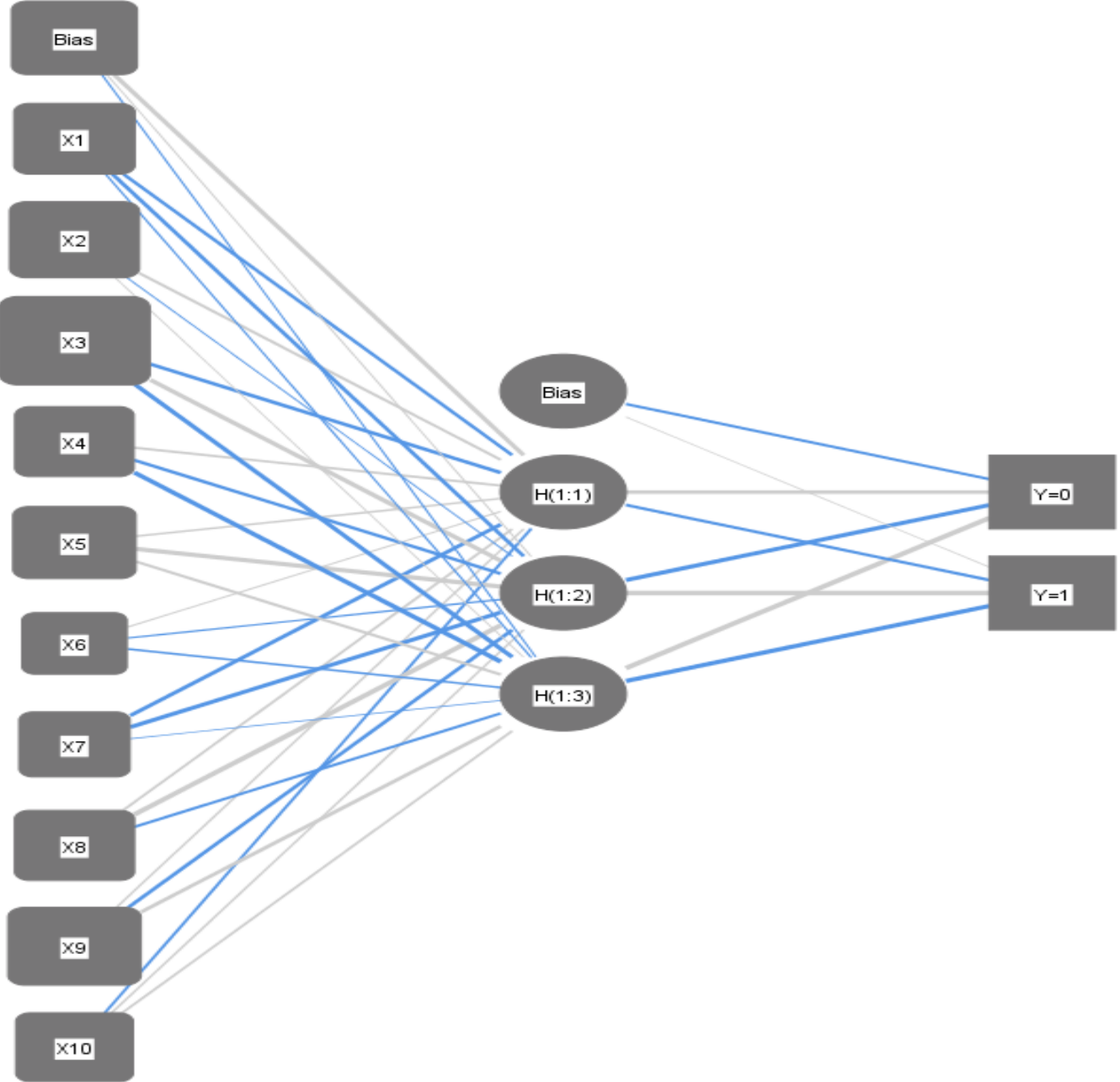

Hidden layer activation function: Hyperbolic tangent Output layer activation function: Softmax

Table 12 Importance of Independent variables in predicting Business Distress in the Arab Region

\begin{tabular}{llcc}
\hline \multicolumn{1}{c}{ Independent Variables } & & Importance & Normalized Importance \\
\hline Cash Cycle & $\mathrm{X}_{3}$ & .225 & $100 \%$ \\
Qatar & $\mathrm{X}_{9}$ & .145 & $64.4 \%$ \\
Operating profit & $\mathrm{X}_{2}$ & .130 & $57.9 \%$ \\
In(Net Fixed Assets) & $\mathrm{X}_{5}$ & .099 & $44 \%$ \\
Leverage & $\mathrm{X}_{1}$ & .091 & $40.2 \%$ \\
Jordan & $\mathrm{X}_{8}$ & .086 & $38.3 \%$ \\
SME Size 1 (Sale) & $\mathrm{X}_{4}$ & .083 & $36.8 \%$ \\
Kuwait & $\mathrm{X}_{10}$ & .076 & $33.6 \%$ \\
Listed SME & $\mathrm{X}_{7}$ & .046 & $20.2 \%$ \\
SME Size 2 (Employees) & $\mathrm{X}_{6}$ & .020 & $8.9 \%$ \\
\hline
\end{tabular}


Figure 4.2: The order of importance of factors in NN model

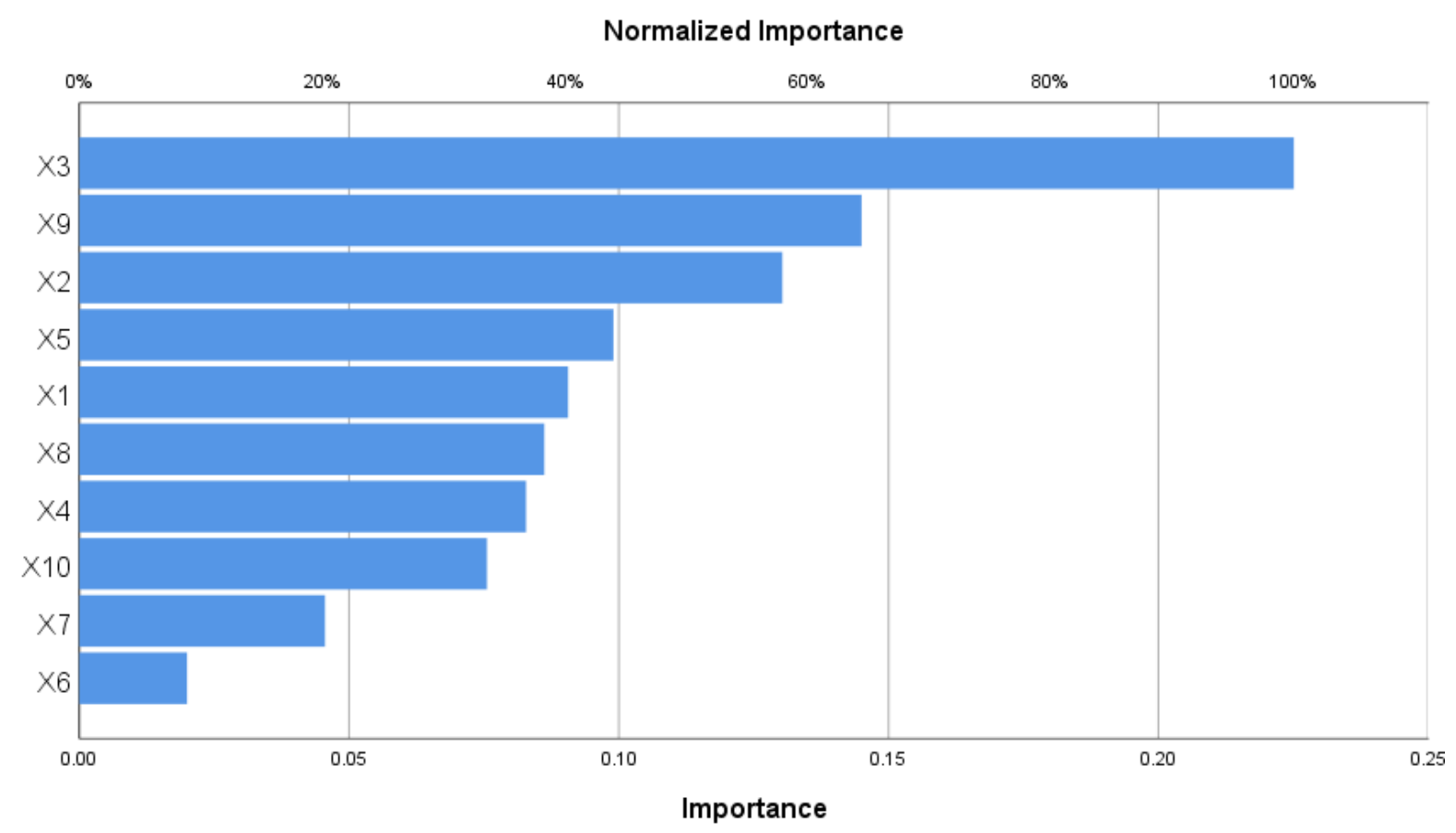

\section{CONCLUSION}

The study examined the determinants of business distress in SME engaged in petrochemical subsectors in the Arab region. A panel data of 140 observations from 28 SME companies for a period of 5 years (2009 2013) is analyzed using panel binary choice models. The result suggests that leverage ratio, cash cycle in days, size of SME fixed asset and SME size (based on number of employees), and listing of SME are key factors in explaining business distress of firms and thus for lenders to consider these factors prudently for making credit decisions by lenders. The study also revealed that lenders may learn from country level experiences in the Arab region. For example, UAE lenders can learn from Qatar SME experiences while other lenders located in Jordan and Kuwait can learn from the UAE lending experiences. Though not expected, the size of SME based on number of employees is found to be significantly higher in non-distressed SME than in the distressed ones. A one percent increase in the number of employees of the SME, the distress probability of such SME declined by 34 percent. The results also validated the existing literature on trade credit, confirming that distressed SME enjoy higher trade credit because they have limited access to formal sources of financing such as banks. The logistic model predicted correctly overall 70 percent of distress and nondistress firms.

On the contrary, neural network model was more flexible and predicted correctly 93 percent in training phase and $83 \%$ in validation phase dominating in predictive behavior over econometric model. NN model indicated that Cash Cycle, operating profit, Net Fixed Assets, and Leverage, were of substantial importance for explaining the distress behavior. Thus, overall NN model dominated the Logistic model in explaining distress behavior of firms.

The sample size and focus on petro-chemical sector were major limitations of this study. With a larger sample size and with different sectors within the Arab region, the prediction power could enhance. Interestingly NN model could prove to be a superior analytical model for lenders to use instead of traditional logistic model. 


\section{REFERENCES}

Abdesamed and AbdWahab (2014). Financing of small and medium enterprises (SMEs): Determinants of bank loan application. African Journal of Business Management. Vol. 8, pp. 717-727.

Abdou, H. and Pointon, J. (2011). Credit scoring, statistical techniques and evaluation criteria: a review of the literature, Intelligent Systems in Accounting, Finance and Management, 18 (2-3), pp. 59-88.

Al Khatib and Al Bzour (2011). Predicting Corporate Bankruptcy of Jordanian Listed Companies: Using Altman and Kida Models. International Journal of Business and Management. Vol. 6, No. 3, P. 208 215

Altman (1968). Financial Ratios, Discriminant Analysis and the Prediction of Corporate Bankruptcy. Journal of Finance, September, p. 589-609.

Altman and Sabato (2007). Modeling Credit Risk for SME: Evidence from the US Market". ABACUS 43, p.

Altman, Sabato, andWilson (2010). The value of non-financial information in small and medium sized enterprises risk management. The Journal of credit risk, p.1-33, Vol. 6.

Beresteanu, Ariel (2003). Nonparametric Estimation of Regression Functions under Restrictions on Partial Derivatives. Working Paper, Department of Economics, Duke University. Webpage: www.econ.duke.edu/ arie/shape.pdf.

Cameron and TRIVEDI (2009). Micro-econometrics Using Stata, Texas, USA, Stata Corp LP.

Central Bank of UAE, IRB guideline (2012). Guidance for the waiver application of Internal Rating Based Approaches for Credit Risk (IRB)". V 1.0

Emine (2012). Financial Challenges That Impede Increasing the Productivity of SME in Arab Region. Journal of Contemporary Management, Academic Research Centre of Canada, P. 17-32. Article ID: 1929-0128-2012-02-17-16.

Gulf news, 17th November 2015.

Gumparthi, Khatri and Manickavasagam (2011). Design and development of credit rating model for public sector banks in India: Special reference to small and medium enterprises. Journal of Accounting and Taxation, Vol. 3(5), P. 105-124,

Hudson (1987). The age, regional and industrial structure of company liquidations, Journal of Business Finance and Accounting, Vol. 14, P. 199-213.

Hashim, and Adbullah (2002). A proposed framework for redefining SME in Malaysia: One Industry one definition. Asian Academy of Management Journal, USM.my P.65-79.

Huei Lin (2009). A cross model study of corporate financial distress prediction in Taiwan: Multiple discriminant analysis, logit, probit and neural networks models. Neurocomputing, Vol. 72, P. 35073516

M. Adnan Aziz, Humayon A. Dar (2004). Predicting Corporate Financial Distress: Where do We Stand? Department of Economics, Loughborough University, UK, p. 1- 40

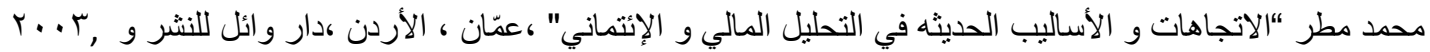
التوزيع (Translation) Matar, Mohamed (2003), Modern Directions and Styles in Financial and Credit Analysis. Amman: Dar Wa'el. $1^{\text {st }}$ Edition

Olutunla and Obamuyi (2008). An empirical analysis of factors associated with the Profitability of Small and medium - enterprises in Nigeria. African Journal of Business Management Vol.2 (x), pp. 195200. 
Ono (2006). The Role of Credit Scoring in Small Business Lending. Mizuho Research Institute, Tokyo, Japan.

Rocha, Farazai, Khouri, and Pearce (2011). The Status of Bank Lending to SME's in the Middle East and North Africa Region. The Union of Arab Banks and the World Bank

Rustichini, Aldo, John Dickhaut, Paolo Ghirardato, Kip Smith, and Jose V. Pardo (2002). A Brain Imaging Study of Procedural Choice. Working Paper, Department of Economics, University of Minnesota. Webpage: http://www.econ.umn.edu/ arust/ProcCh3.pdf.

Rosli (2011). Determinants of small and medium enterprises performance in the Malaysian autoparts industry. African Journal of Business Management. Vol. 5, pp. 8235-8241,

Shumway (2001). Forecasting Bankruptcy more accurately: A Simple Hazard Rate Model. Journal of Business, Vol.74, pp. 101-124.

Yu Cao (2011). A survival analysis of small and medium enterprises (SMEs) in central China and their determinants. African Journal of Business Management. Vol. 6, P. 3834-3850

\section{NOTES}

\footnotetext{
iUnion of Arab Banks Statistics 2009.

i"World Investment report published in 2013.

iiiAbu Dhabi Islamic Bank Annual report 2013.

ivEmirates NBD Group's Annual Report 2013.

${ }^{\mathrm{A} A r a b}$ Bank Plc Annual Report 2013.
}

viAs per Central Bank of UAE (CBUAE) Banks in the UAE will be permitted to calculate their minimum capital requirements for credit risk on the basis of their own internal estimates of risk components, also known as the Internal Ratings Based (IRB) approach, subject to prior approval from CBUAE. So there are now two approaches for Internal Ratings Based; Foundation (F-IRB) and Advanced (A-IRB). This was not allowed before. But still the two approaches should be implemented according to specific steps highlighted in framework. The risk attributes for IRB are loss given default, exposure at default, credit conversion factor, maturity. It is crucial for banks that internal ratings and default and loss estimates are used as a key component of measuring and managing credit risk (not only for regulatory purposes but also for internal purposes), this estimate should assist the banks in decision-making process of banks as well as credit approval, account management of clients, in addition to internal capital allocation and corporate governance functions of the bank.

viiGCC Petrochemical and Chemical (GPCA) Facts and Figures 2012.

viii Extract from Article 2 of the Annex of Recommendation 2003/361/EC. The definition Implemented effectively on January $1^{\text {st }} 2005$.

${ }^{i x}$ Of course, classification has wider applications, especially in the health sciences. For example, neural networks have proven very useful for detection of high or low risks of various forms of cancer, based on information from blood samples and imaging.

${ }^{x}$ Applying this concept to finance, if the Fed raises the short-term interest rate, how should portfolio managers shift their assets? Knowing how the short-term rates affect a variety of rates of return and how they will affect the future inflation rate can lead to the formulation of a reaction function, in which financial officers shift from risky assets to higher-yield, risk-free assets. We call such a policy function, based on the "laws of motion" of the system, control. Business organizations by their nature are interested in diagnostics and prediction so that they may formulate policy functions for effective control of their own future welfare.

${ }^{x i}$ Most problems we work with, fortunately, do not involve a large number of neurons engaging in parallel processing, thus the parallel processing advantage, which applies to the way the brain works with its massive number of neurons, is not a major issue.

xii Of course, very simple input sensory data, such as the experience of heat or cold, need not lead to processing by very many neurons in multiple hidden layers to produce the recognition or insight that it is time to turn up the heat or turn on the air conditioner. As experiences of input sensory data become more complex or diverse, more hidden neurons 
are activated, and insight as well as decision is a result of proper weighting or combining signals from many neurons, perhaps in many hidden layers. A commonly used application of this type of network is in pattern recognition in neural linguistics, in which handwritten letters of the alphabet are decoded or interpreted by networks for machine translation.

xiii Keynes referred quite often to "animal spirits" of investors in times of boom and bust, and we often refer to bullish (optimistic) or bearish (pessimistic) markets.

xiv The dependent and independent variables can potentially vary according to both time and the individual company characteristics. Variation over time for a given company is called within variation, and variation across individuals (i.e. companies) only is called to between variation. This distinction is important because estimators differ in their use of within and between variation. Due to the time-variant of the variables, within and between variation tests should be done. Time-invariant variables will have zero within variation. Similarly, individual-invariant variables will have zero variation. The two qualitative variables - the size category of SME and being listed or not - both are time-invariant variables and will have zero within variation. Moreover, there may still be unobserved factors that affect the performance of the company and may be highly correlated with one or more independent variables-such as: management quality, ownership style (partnership, family ownership, etc.). Such factors should be taken into consideration. Therefore, we need to check the fixed effect model, where the unobserved variable is closely related to an independent variable. On the other hand, the random effect model should also be tested, where the unobserved variable has no correlation with independent variables.-Moreover, we felt that there may still be some hidden errors and variations among the 140 observations that needed to be minimized. Consequently, we estimated logistic models which include year-dummy variable (2009 to 2013). This specification minimizes the variations among the observation. 